\title{
CONSTITUIÇÃO DE CORPUS ELETRÔNICO PARA ANOTAÇÃO SINTÁTICA: EDIÇÃO EM LINGUAGEM XML DE PANFLETOS
}

\author{
$\underline{\text { Rhillary Lopes Vieira }}{ }^{1}$; Mariana Fagundes de Oliveira Lacerda ${ }^{2}$ \\ 1. Bolsista PIBIC/FAPESB, Graduanda em Letras Vernáculas, Universidade Estadual de Feira de Santana, e-mail: \\ rhillaryvieira@hotmail.com \\ 2. Orientadora, Departamento de Letras e Artes, Universidade Estadual de Feira de Santana, e-mail: \\ marianafag@gmail.com
}

PALAVRAS-CHAVE: Humanidades Digitais; eDictor; Banco de dados.

\section{INTRODUÇÃOO}

O presente trabalho faz parte da agenda do projeto CEDOHS-Corpus Eletrônico de Documentos Históricos do Sertão, o qual compõe o Núcleo de Estudos em Língua Portuguesa (NELP), situado no Departamento de Letras e Artes da Universidade Estadual de Feira de Santana (UEFS).

O trabalho de reconstituição da história da língua tem como ponto de partida a constituição de corpus, e, segundo Mattos e Silva (2002), o corpora deve ser diverso, constituído por textos de diferentes tipos e escritos em diferentes épocas. Dessa forma, a formação de um banco de dados com textos históricos é de grande importância para estudos na área da linguística histórica.

Pensando nisso, como parte da agenda do CEDOHS, o objetivo neste trabalho foi editar, em linguagem XML, de 57 panfletos de Eulálio Motta, produzidos em Mundo NovoBahia, entre 1930 e 1980. A edição eletrônica dos panfletos foi feita a partir da edição filológica feita por Barreiros (2013). Essa conciliação das novas tecnologias digitais e da antiga filologia traz novas possibilidades para preservação e análise de textos antigos (GONÇALVES; BANZA, 2013), contribuindo, assim, para avanços nos estudos diacrônicos da língua.

Para a edição eletrônica, utilizou-se o eDictor, ferramenta desenvolvida por Kepler, Paixão de Sousa e Farias (2007), programa computacional voltado para a análise linguística automática, que permite a transcrição e codificação em formato XML e facilita a edição eletrônica de textos antigos.

\section{MATERIAL E MÉTODOS OU METODOLOGIA (ou equivalente)}

Os 57 panfletos editados foram produzidos por Eulálio de Miranda Motta, em Mundo Novo-Bahia, no período entre 1930 e 1980. O escritor, que nasceu em Mundo Novo no ano de 1907, tornou-se uma figura histórica no município, fazendo da escrita uma forma de se colocar no mundo e de criar própria identidade.

Vale ressaltar que os panfletos já haviam sido editados filologicamente por Barreiros (2013). Para edição eletrônica, em linguagem XML, foi utilizado o eDictor (KEPLER, PAIXÃO DE SOUSA E FARIA, 2007), ferramenta desenvolvida para a edição eletrônica e análise linguística automática. 


\section{RESULTADOS E/OU DISCUSSÃO (ou Análise e discussão dos resultados)}

A edição eletrônica do panfletos no eDictor seguiu os critérios de edição do projeto CEDOHS. Já editados filologicamente, os textos ganharam, no eDictor, uma versão modernizada, com padronização da ortografia, acentuação, desenvolvimento de abreviaturas, junção de palavras. Essas modificações ficam salvas e visíveis, assim como suas versões originais. Por outro lado, mesmo na versão modernizada, algumas características do texto não são modificadas, como mudanças de parágrafo, de linha e de página. A seguir, alguns exemplos das edições digitais:

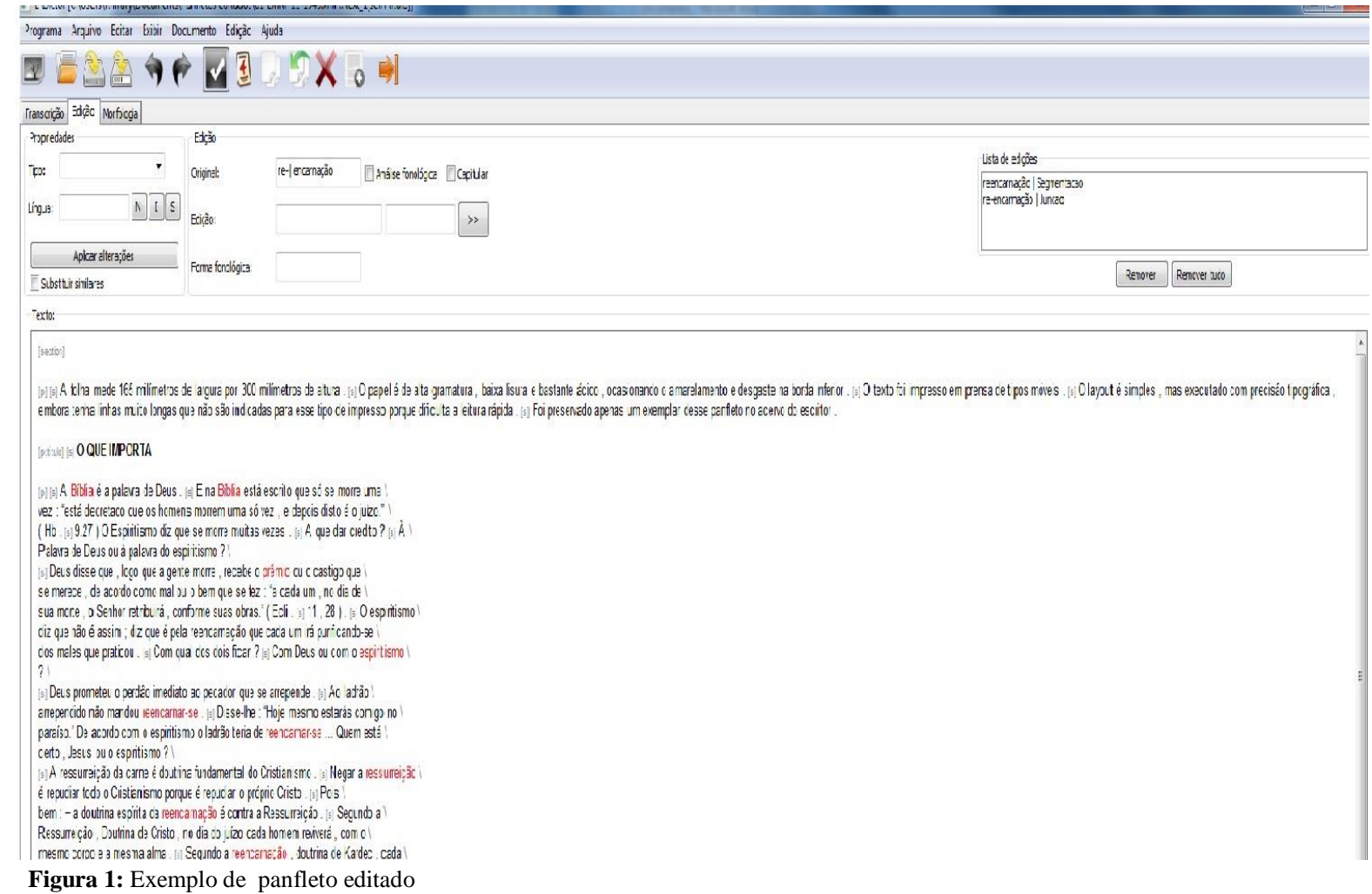

Na Figura 1, as palavras em vermelho sofreram alguma modernização, que fica visível na barra do canto superior direito.

Os metadados de cada panfleto também foram preenchidos. Contém informações como autor, temática, local, tipo de testemunho, como é possível notar na Figura 2 a seguir: 


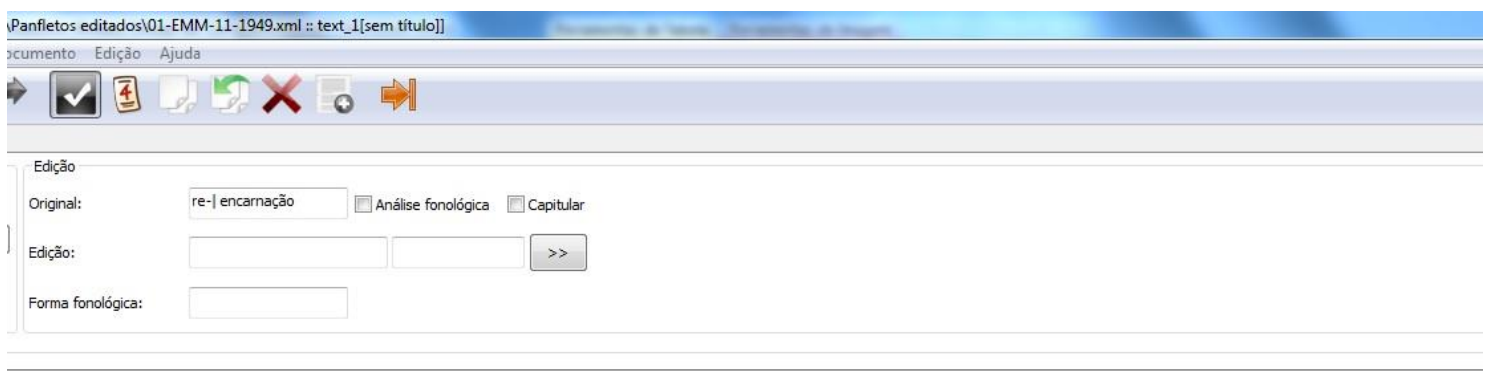

de largura por 300 milimetros de altura . [s] $\mathrm{O}$ papel é de alta gramatura , baixa lisura e bastante ácido, ocasionando o amarelamento e desgaste na borda inferior . [s] $\mathrm{O}$ texto foi impresso em । que nẫo são indicadas para esse tipo de impresso porque dificulta a leitura rápida . [s] Foi preservado apenas um exemplar desse panfleto no acervo do escritor.

[s] E na Biblia está escrito que só se morre uma

ns morrem uma só vez, e depois disto é o juizo." ।

ue se morre muitas vezes is] A que dar credito ? [s] A

the morre

o prêmio ou o castigo que

informe suas obras." (Ecli . [s] 11, 28). [s] O espiritismo

la reencarnação que cada um irá purificando-se

ual dos dois ficar? [s] Com Deus ou com o espiritismo

to ao pecador que se arrepende. [s] Ao ladrão

r-se. [s] Disse-the : "Hoje mesmo estarás comigo no

mo o ladrão teria de reencarnar-se ... Quem está

ina fundamental do Cristianismo - [s] Negar a ressurreição

jue é repudiar o próprio Cristo - [s] Pois

arnação é contra a Ressurreiçẫo - [s] Segundo

no dia do juizo cada homem reviverá, como 0

Segundo a reencarnaçäo, doutrina de Kardec, cada

Is: Cristo pregou a Ressurreição ; Kardec pregou a reencarnação

rencarnação é mentira ; se a reencarnação

erro - [s] Daqui não temos para onde fugir : ou

ado ; ou Kardec está certo e Jesus está errado.

[s] Kardec afirmou expressamente : - " ... não se pode admitif

los Espiritos, pagina 458 ) Cristo pregou a

o se pode admitir a Ressurreição. . Como que ficamos

Figura 2: Metadados do panfleto editado

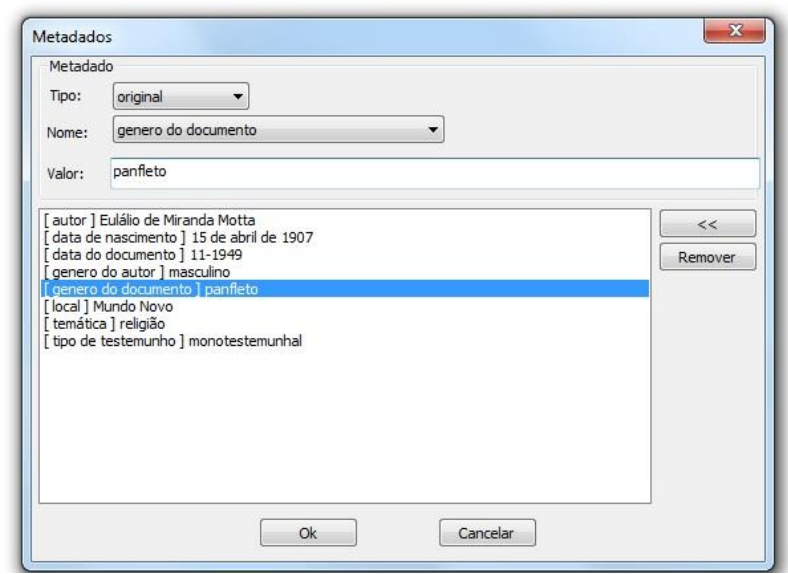

A edição completa dos 57 panfletos estará disponível no site do CE-DOHS (www.uefs.br/cedohs) .

\section{CONSIDERAÇÕES FINAIS (ou Conclusão)}

A constituição de corpus eletrônico serve como fonte para a reconstrução da história da língua, sendo assim, um trabalho importante para a linguística histórica. Dessa forma, o objetivo principal deste trabalho foi editar, em linguagem XML, 57 panfletos preservados de Eulálio Motta. Esse objetivo foi concluído com êxito, contribuindo para facilitar futuras pesquisas no corpus, não apenas em análises de aspectos linguísticos, mas sócio-históricos, econômicos, políticos.

\section{REFERÊNCIAS}

BARREIROS, P. N. O Pasquineiro da roça: edição dos panfletos de Eulálio Motta. 386f. Tese (Doutorado em Letras) - Instituto de Letras - Universidade Federal da Bahia, Salvador, 2013.

GONÇALVES, M. F.; BANZA, A. P. (org.). Património textual e humanidades digitais: da antiga à nova Filologia. Évora: CIDEHUS, 2013.

MATTOS E SILVA, R. V. Para a história do português culto e popular brasileiro: sugestões para uma pauta de pesquisa. In: ALKMIM, Tânia M. Para a história do português brasileiro: novos estudos. São Paulo: Humanitas/FFCHL/USP: FAPESP, 2002, v. 2, p. 443-464.

PAIXÃO DE SOUSA, M. C.; KEPLER, F. N.; FARIA, P. E-dictor: Novas perspectivas na codificação e edição de corpora de textos históricos. In: Anais do VIII Encontro de 
Linguística de Corpus, realizado na UERJ, 13 a 14 de novembro de 2009. Rio de Janeiro, 2009. p. 69-105.

PROJETO CORPUS ELETRÔNICO DE DOCUMENTOS HISTÓRICOS DO SERTÃO (disponível em http://www.uefs.br/cedohs/), 2011. 